\title{
Quantitative Clinical Diagnostic Analysis of Acetone in Human Blood by HPLC: A Metabolomic Search for Acetone as Indicator
}

\author{
Esin Akgul Kalkan, ${ }^{1}$ Mehtap Sahiner, ${ }^{2}$ Dilek Ulker Cakir, ${ }^{3}$ \\ Duygu Alpaslan, ${ }^{4}$ and Selehattin Yilmaz ${ }^{5}$ \\ ${ }^{1}$ Department of Forensic Medicine, Faculty of Medicine, Canakkale Onsekiz Mart University, \\ Terzioglu Campus, 17020 Canakkale, Turkey \\ ${ }^{2}$ Department of Leather Engineering, Faculty of Engineering, Ege University, Bornova, 35100 İzmir, Turkey \\ ${ }^{3}$ Department of Clinical Biochemistry, Faculty of Medicine, Canakkale Onsekiz Mart University, Terzioglu Campus, \\ 17020 Canakkale, Turkey \\ ${ }^{4}$ Department of Chemical Engineering, Faculty of Engineering, Yuzuncu Yil University, 65080 Van, Turkey \\ ${ }^{5}$ Department of Chemistry, Faculty of Sciences and Arts, Canakkale Onsekiz Mart University, Terzioglu Campus, \\ 17020 Canakkale, Turkey
}

Correspondence should be addressed to Selehattin Yilmaz; seletyilmaz@hotmail.com

Received 13 February 2016; Revised 26 April 2016; Accepted 4 May 2016

Academic Editor: Mohamed Abdel-Rehim

Copyright (c) 2016 Esin Akgul Kalkan et al. This is an open access article distributed under the Creative Commons Attribution License, which permits unrestricted use, distribution, and reproduction in any medium, provided the original work is properly cited.

Using high-performance liquid chromatography (HPLC) and 2,4-dinitrophenylhydrazine (2,4-DNPH) as a derivatizing reagent, an analytical method was developed for the quantitative determination of acetone in human blood. The determination was carried out at $365 \mathrm{~nm}$ using an ultraviolet-visible (UV-Vis) diode array detector (DAD). For acetone as its 2,4-dinitrophenylhydrazone derivative, a good separation was achieved with a ThermoAcclaim $\mathrm{C}_{18}$ column $(15 \mathrm{~cm} \times 4.6 \mathrm{~mm} \times 3 \mu \mathrm{m})$ at retention time $\left(t_{\mathrm{R}}\right)$

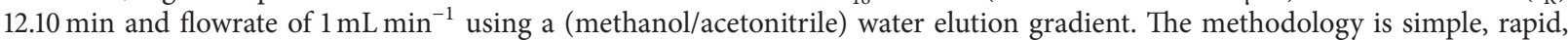
sensitive, and of low cost, exhibits good reproducibility, and allows the analysis of acetone in biological fluids. A calibration curve was obtained for acetone using its standard solutions in acetonitrile. Quantitative analysis of acetone in human blood was successfully carried out using this calibration graph. The applied method was validated in parameters of linearity, limit of detection and quantification, accuracy, and precision. We also present acetone as a useful tool for the HPLC-based metabolomic investigation of endogenous metabolism and quantitative clinical diagnostic analysis.

\section{Introduction}

Acetone is the simplest ketone compound. In general, acetone is not considered harmful, and the World Health Organization has not classified acetone as carcinogenic. However, its prolonged inhalation can not only cause irritation of the mucous membranes, headaches, confusion, and narcotic effects, but lead to coma as well [1-5].

For etiological reasons, acetonaemia is classified to be of endogenous and exogenous origin [6,7]. Multiple toxicities and physiopathological conditions result in ketosis (acetonaemia particularly), including diabetes mellitus (DM), starvation coupled with physiologic stress, prolonged exercise, during pregnancy, and ethanol toxicity, other alcohol ingestions, drug toxicities, inborn errors of ketone metabolism, alcoholic ketoacidosis, delirium tremens, and hypothermia [6-9]. DM is a disease involving environmental and genetic factors. The main symptom of DM is a high blood glucose concentration depending on insulin deficiency. In this case the body cannot fully use glucose but could use fatty metabolism instead of glucose for energy [9]. DM, especially diabetes and autoimmune associated diseases, thyroid disease, and diseases that can accompany diabetes (hypertension, cardiovascular disease, cerebrovascular disease, and renal insufficiency) can cause pathological changes in most of the tissues, organs, and biological fluids depending on lipotoxicity and glucotoxicity. 
A lot of medical, chemical, and medicolegal investigations have been carried out with the determination of acetone in blood and other biological fluids $[2,6,7,10]$. Over the decades, several methods have been used for its determination in biological samples. In the beginning, colorimetric methods were developed and used for the determination of acetone in plasma [11-13]. These methods have common disadvantages such as the lack of specificity and detection limit. In recent decades, gas chromatographs equipped with flame ionization detectors or mass spectrometric detectors have been developed for determination of acetone concentrations in body fluids and in expired air [14-18]. Enzymatic methods are more specific but more complex and have long assay times and gas chromatographic methods, although widely used, are applied with difficulty as routine tests [2]. The determination of acetone in the blood is most important in clinical diagnostic laboratory studies. There are three ketone bodies, while the two main ketone bodies are acetoacetate (AcAc) and 3-b-hydroxybutyrate (3HB), the third ketone body; acetone (Ac) is found minimum level [9]. Ketone bodies are produced by the liver and used peripherally as an energy source when glucose is not readily available $[9,19]$. Ketone bodies are three water-soluble compounds that are produced as by-products when fatty acids are broken down for energy in the liver and kidney [19]. Ketone bodies are produced from acetyl-CoA mainly in the mitochondrial matrix of hepatocytes when carbohydrates are so scarce that energy must be obtained from breaking down fatty acids $[9,20]$. Also, acetone is produced by spontaneous decarboxylation of acetoacetate [6-9]. Acetone cannot be converted back to acetyl-CoA, so it is excreted in the urine or exhaled [21]. Recently, blood or urine testing kits have been used to test for the presence of acetone in clinical biochemistry laboratories. Acetone can also be quantified by sampling the human blood and testing by gas chromatography [22]. Brega et al. described a rapid and simple HPLC procedure that can be used for the routine measurement of acetone in biological fluids, such as plasma and urine. According to Fujii et al., it is proposed that liquid chromatography with fluorescence (LC-FL) seems to be useful for the determination of acetone in the saliva [23].

In this paper, we present a rapid and simple HPLC technique using 2,4-DNPH as a derivatizing reagent for quantitative determination and metabolomic research of acetone in biological fluid such as human blood.

\section{Material and Methods}

2.1. Reagents and Standards. 2,4-DNPH (Sigma-Aldrich, 97\%), acetone (Merck, 99.8\%), acetonitrile (Sigma-Aldrich, 99.8\%), and methanol (Merck, 99.8\%) were used in this study. All other chemicals were of analytical reagent grade and used without further purification.

2.2. Instrumentation. For the chromatographic analysis, Thermo Scientific Dionex Ultimate 3000 HPLC with a ThermoAcclaim- $\mathrm{C}_{18}(15 \mathrm{~cm} \times 4.6 \mathrm{~mm} \times 3 \mu \mathrm{m})$ column and UV-Vis DAD were used. The deionized water was 18.2 $\mathrm{M} \Omega \cdot \mathrm{cm}$ (Millipore Direct-Q3 UV) and was used throughout the experiments. For the biochemical analyses,
Cobas 6000 (Roche, Germany) autoanalyzer was used for blood glucose levels. Qualitative analysis of total ketones in urine was evaluated by Iris Iricel 2000 Analyzer (Icem Velocity).

\subsection{Sample Collection and Procedure for the Determination} of Acetone in Human Blood. In the first stage of our study, following a 12-hour fasting venous blood samples were taken from patients admitted to hospital of the Faculty of Medicine, Canakkale Onsekiz Mart University. The human blood and urine samples were directly collected into a tube (without a collection device) between 08:30 and 11:00 am. Clinical Biochemistry Laboratory blood and urine glucose tests were studied for routine biochemistry using a urine autoanalyzer. Test results were screened for hyperglycemia and ketonuria. The patients were divided into high blood glucose and urine ketone positive subjects (Group 1) and high blood glucose and urine ketone negative example subjects (Group 2). The patients with hyperglycemia were 8 females and 7 males (age: $21-87 ; n=15$ ), while 5 female and 2 male patients had positive urine ketones (age: $21-68, n=7$ ) and 5 male and 3 female patients had negative urine ketones (age: $55-87, n=8$ ). The blood glucose levels varied between 110 and $320 \mathrm{mg} / \mathrm{dL}$ in our patients (Table 1).

In the second stage of the study, to determine the probable positive acetone, its quantitative analysis was carried out in biological fluids using the HPLC technique. The blood samples were immediately prepared for HPLC analysis carried out within 8 hours after sample collection. A method for the determination of acetone in human blood by HPLC was developed. Plasma specimens were deproteinized with acetonitrile $(1: 1, \mathrm{v} / \mathrm{v}) ; 2,4-\mathrm{DNPH}$ is added to the supernatant (filtered blood samples) and treated with acetonitrile $(2: 1$, $\mathrm{v} / \mathrm{v})$ to prevent crystallization of the synthesized phenylhydrazone. An aliquot (20 microliters) of the reaction mixture was subjected to HPLC at ambient temperature using ThermoAcclaim- $\mathrm{C}_{18}(15 \mathrm{~cm} \times 4.6 \mathrm{~mm} \times 3 \mu \mathrm{m})$ column and $\mathrm{UV}-\mathrm{Vis} \mathrm{DAD}$ with (methanol/acetonitrile) water as eluent at a flowrate of $1 \mathrm{~mL} \mathrm{~min}^{-1}$ and detection at $365 \mathrm{~nm}[2,3]$. The experimental procedures were conducted in accordance with the ethical standards of the Helsinki Declaration and approved by the Canakkale Onsekiz Mart University Human Research Ethics Committee. Written informed consent was obtained from all the subjects.

2.4. Acetone Labeling and HPLC Analysis. The quantitative analysis of acetone using HPLC was performed after labeling with 2,4-DNPH. The 2,4-dinitrophenylhydrazone standards were prepared by mixing A and B solutions: (A): $0.40 \mathrm{~g}$ of 2,4DNPH dissolved in $2.00 \mathrm{~mL}$ of $\mathrm{H}_{2} \mathrm{SO}_{4}+3.00 \mathrm{~mL}$ of $\mathrm{H}_{2} \mathrm{O}+$ $10.0 \mathrm{~mL}$ ethanol; (B): $0.50 \mathrm{~g}$ or $1.00 \mathrm{~mL}$ of the acetone standard dissolved in $20.0 \mathrm{~mL}$ ethanol. After this mixing, a precipitate was formed in each case, isolated through filtration, and dried in vacuum $[3,24,25]$.

Acetone was added into its 2,4-DNPH derivatives by mixing $1.00 \mathrm{~mL}$ of a solution containing $200 \mathrm{mg} / 100 \mathrm{~mL}$ of 2,4-DNPH with $1.0 \mathrm{~mL}$ of $\mathrm{H}_{3} \mathrm{PO}_{4}$, and $4.00 \mathrm{~mL}$ of the human serum. After $2 \mathrm{~h}$, a $40.0 \mu \mathrm{L}$ aliquot was withdrawn and analyzed by the HPLC technique [3, 24-27]. Chromatographic 
TABLE 1: Quantitative analysis data of acetone as its 2,4-dinitrophenylhydrazone derivative in human blood by HPLC.

\begin{tabular}{|c|c|c|c|c|c|c|}
\hline Sample & Subject & Sex & Age & Blood glucose & Urine ketone & $\begin{array}{l}\text { Acetone levels by HPLC (mean value } \pm \mathrm{sd} .)^{*} \\
\text { Blood }\left(\mathrm{mmol} \mathrm{L}^{-1}\right)^{* *}\end{array}$ \\
\hline \multicolumn{7}{|l|}{ Group 1} \\
\hline 1 & $\begin{array}{l}\text { Type } 1 \text { diabetes mellitus, Hashimoto } \\
\text { disease, systemic lupus } \\
\text { erythematosus }\end{array}$ & F & 21 & 197 & ++ & $15.00 \pm 1.00$ \\
\hline 2 & Diabetes mellitus (DM), pneumonia & M & 68 & 320 & + & $2.40 \pm 0.20$ \\
\hline 3 & DM, obesity, depression & $\mathrm{F}$ & 33 & 196 & + & $3.86 \pm 0.10$ \\
\hline 4 & Acute pancreatitis & M & 60 & 134 & + & $0.013 \pm 0.001$ \\
\hline 5 & $\begin{array}{l}\text { Acute pancreatitis, obesity, } \\
\text { hyperlipidemia }\end{array}$ & $\mathrm{F}$ & 33 & 117 & + & $0.22 \pm 0.01$ \\
\hline 6 & $\mathrm{DM}$ & $\mathrm{F}$ & 37 & 175 & + & $0.24 \pm 0.01$ \\
\hline 7 & Gestational DM & $\mathrm{F}$ & 37 & 74 & +++ & $17.27 \pm 1.00$ \\
\hline \multicolumn{7}{|l|}{ Group 2} \\
\hline 8 & DM, hypothyroidemia & M & 80 & 340 & - & $0.42 \pm 0.01$ \\
\hline 9 & DM, hypertension & $\mathrm{F}$ & 82 & 248 & - & $3.20 \pm 0.10$ \\
\hline 10 & $\begin{array}{l}\text { DM, hypertension, cerebrovascular } \\
\text { disease, acute kidney failure }\end{array}$ & $\mathrm{F}$ & 77 & 202 & - & $3.10 \pm 0.10$ \\
\hline 11 & $\begin{array}{l}\text { Anemia, hypothyroidemia, } \\
\text { hyperlipidemia }\end{array}$ & M & 52 & 110 & - & $0.033 \pm 0.01$ \\
\hline 12 & DM, hypertension, hyperlipidemia & $\mathrm{F}$ & 55 & 137 & - & $1.53 \pm 0.01$ \\
\hline 13 & $\begin{array}{l}\text { Hypertension, congestive heart } \\
\text { disease, chronic obstructive } \\
\text { pulmonary disease, cerebrovascular } \\
\text { disease }\end{array}$ & M & 83 & 182 & - & $1.51 \pm 0.01$ \\
\hline 14 & $\begin{array}{l}\text { DM, larynx carcinoma, } \\
\text { hypothyroidemia }\end{array}$ & M & 59 & 177 & - & $1.54 \pm 0.01$ \\
\hline 15 & $\begin{array}{l}\text { Hepatic failure, hypertension, } \\
\text { chronic kidney failure }\end{array}$ & $\mathrm{M}$ & 87 & 111 & - & $2.13 \pm 0.10$ \\
\hline
\end{tabular}

separation was achieved in a ThermoAcclaim- $\mathrm{C}_{18}(15 \mathrm{~cm} \times$ $4.6 \mathrm{~mm} \times 3 \mu \mathrm{m})$ column at UV-Vis DAD detector $\left(\lambda_{\max }\right.$ $365 \mathrm{~nm}$ ). The injection volume was $20.0 \mu \mathrm{L}$ and the detection was performed at $365 \mathrm{~nm}$. The following gradient was used: (methanol/acetonitrile) $(8: 2)$ water $60: 40(\mathrm{v} / \mathrm{v})$. Elution was achieved at retention time $\left(t_{\mathrm{R}}\right) 12.10$ and flow-rate of $1 \mathrm{~mL} \min ^{-1}$.

2.5. Preparation of Calibration Standards. Standard calibration curve was prepared with acetone (0.5, 2.5, 5.0, 10 , and $20 \mathrm{mmol} \mathrm{L}^{-1}$ ) and $40 \mu \mathrm{L} 2,4-\mathrm{DNPH}$ in acetonitrile. Human samples were prepared by adding $40 \mu \mathrm{L} 2,4$ DNPH and $500 \mu \mathrm{L}$ acetonitrile to $200 \mu \mathrm{L}$ human serum. The calibration curve was constructed by plotting the peak area of the 2,4-DNPH derivative of acetone $(y)$ versus the concentration of acetone $\left(x, \mathrm{mmol} \mathrm{L}^{-1}\right)$ by linear regression $(n=4)$. The equation was found as $y=$ $0.7361 x+0.0877$ with a 0.9967 , correlation coefficient $(R)$.

2.6. Method Validation. The method proposed was validated as described in ICH guidelines in parameters of linearity, limit of detection and quantification, accuracy, and precision [28].
2.6.1. Linearity. The linearity of the method was determined at four concentration levels ranging from 0.5 to $20 \mathrm{mmol} \mathrm{L}^{-1}$. The calibration curves were constructed by plotting the peak area of the 2,4-DNPH derivative of acetone $(y)$ versus concentration of acetone $(x)$. The slope, $y$-intercept, and correlation coefficient were calculated. To check the linearity, $F$ test also was applied [28-33].

2.6.2. Limit of Detection (LOD) and Limit of Quantification (LOQ). The LOD was estimated using signal-to-noise ratio of $3: 1$ or $(3 \mathrm{~s} / \mathrm{m})$ and LOQ as $10: 1$ or $(10 \mathrm{~s} / \mathrm{m})$, at which accuracy and standard deviation were within $20 \%$ as per ICH $[28,32$, $34,35]$.

2.6.3. Accuracy and Precision. Intraday accuracy and precision were performed for acetone at $5.0 \mathrm{mmol} \mathrm{L}^{-1}$ in replicate $(n=3)$. Interday accuracy and precision were achieved on three different days. Accuracy (expressed as recovery) and precision (expressed as relative standard deviation) should not deviate by $\pm 15 \%$ of the nominal concentration [34].

\section{Results and Discussion}

3.1. The Chromatogram of 2,4-DNPH. Elution and recovery problems were solved using HPLC with 2,4-DNPH as 
TABLE 2: Intraday and interday precision and accuracy of the applied method.

\begin{tabular}{lcccrrr}
\hline Analyte & Period of analysis & $\begin{array}{c}\text { Nominal concentration } \\
\mathrm{mmol} \mathrm{L}^{-1}\end{array}$ & $\begin{array}{c}\text { Mean concentration found } \\
\mathrm{mmol} \mathrm{L}^{-1}\end{array}$ & Recovery\% & RSD\% \\
\hline \multirow{2}{*}{ Acetone } & Intraday & 0.50 & $0.49 \pm 0.01$ & 98 & 2.04 \\
& Interday & 0.50 & $0.48 \pm 0.01$ & 36 & 2.10 \\
\hline
\end{tabular}

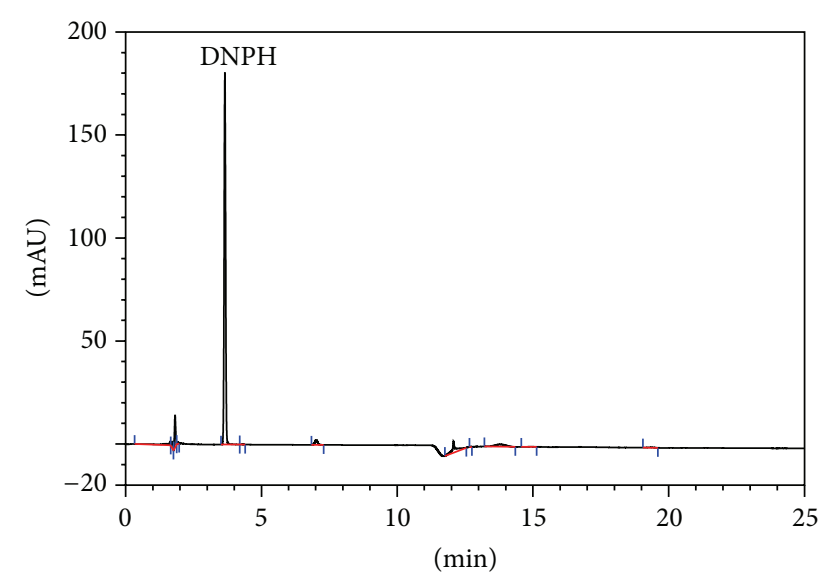

Figure 1: The chromatogram of 2,4-DNPH; for chromatographic conditions: see Section 2.

derivatizing reagent. The chromatogram of $2,4-\mathrm{DNPH}$ is given in Figure 1. As can be seen from Figure 1, the retention time $\left(t_{\mathrm{R}}\right)$ was obtained as $3.80 \mathrm{~min}$.

\subsection{Typical HPLC Chromatogram of Acetone as Its 2,4-DNPH} Derivative. The most efficient separation of acetone as its 2,4-DNPH was obtained with a ThermoAcclaim $\mathrm{C}_{18}$ column $(15 \mathrm{~cm} \times 4.6 \mathrm{~mm} \times 3 \mu \mathrm{m})$ at retention time $\left(t_{\mathrm{R}}\right) 12.10 \mathrm{~min}$ and flowrate of $1 \mathrm{~mL} \mathrm{m^{-1 }}$ using a (methanol/acetonitrile) water elution gradient. No elution problem for acetone as its 2,4-dinitrophenylhydrazone derivative was observed. Typical HPLC chromatogram of $0.681 \mathrm{mmol} \mathrm{L}^{-1}$ acetone as its 2,4DNPH derivative is given in Figure 2.

3.3. Determination of Acetone in Human Blood by HPLC. The HPLC chromatogram of $15 \mathrm{mmol} \mathrm{L}^{-1}$ acetone in human blood in the first patient of Group 1 is given in Figure 3.

3.4. Quantitative Determination of Acetone in Patients. In our study, the patients were determined as high blood glucose and urine ketone positive subjects (Group 1) and high blood glucose and urine ketone negative example subjects (Group 2). Test results were screened for hyperglycemia and ketonuria. The blood glucose levels, given in Table 1, vary between 110 and $320 \mathrm{mg} / \mathrm{dL}$ in our patients, except for sample 7. Many patients in our study have DM disease, except samples numbered 4, 5, 11, 13, and 15 (Table 1).

\subsection{Method Validation}

3.5.1. Linearity. The calibration plot of peak area against concentration was obtained linear in the range 0.5 to

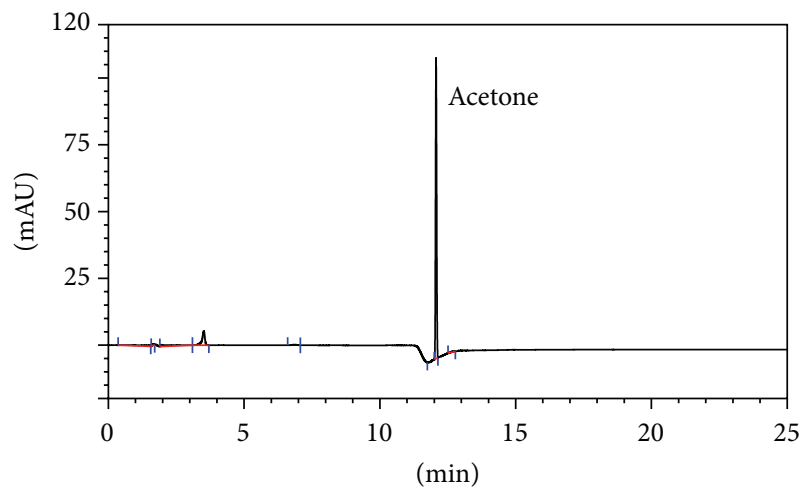

FIGURE 2: : Typical HPLC chromatogram of $0.681 \mathrm{mmol} \mathrm{L}^{-1}$ acetone as its 2,4-DNPH derivative; for chromatographic conditions: see Section 2 .

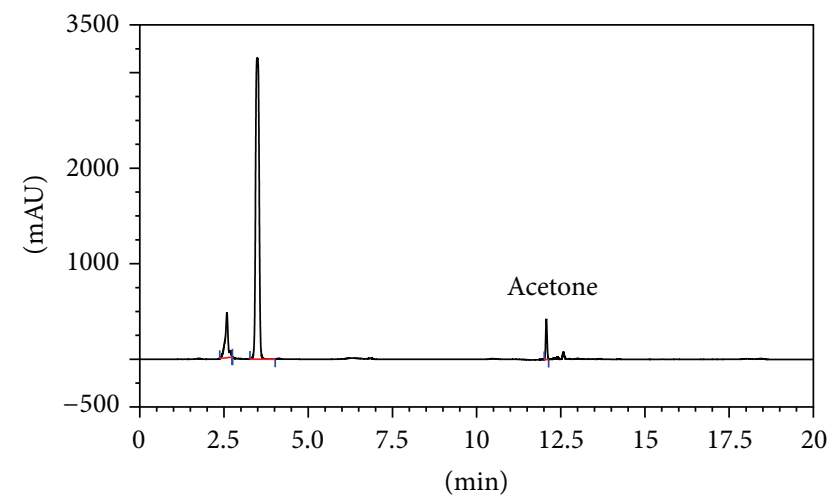

FIgURE 3: The HPLC chromatogram of $15 \mathrm{mmol} \mathrm{L}^{-1}$ acetone in human blood from first patient of Group 1; for chromatographic conditions: see Section 2.

$20 \mathrm{mmol} \mathrm{L}^{-1}$. The regression equation and correlation coefficient were obtained as $y=0.7361 x+0.0877$ with a 0.9967 , correlation coefficient $(R)$.

$F$ test applied to accuracy of calibration curve. For calibration curve, $F_{\text {critical }}$ value at 12 degrees of freedom $(p=$ 0.05 ) is 2.20. Experimental $F$ value is obtained as 1.26 . So this value is smaller than 2.2, and calibration curve is linear. For the human plasma samples, $F_{\text {critical }}$ value for calibration curve at 3 degrees of freedom $(p=0.05)$ is 3.18. Experimental value is obtained as 2.03. So, this value is smaller than $F_{\text {critical }}$ value, and obtained values are appropriate.

3.5.2. Limit of Detection and Quantification. The LOD and LOQ were found as 0.041 and $0.136 \mathrm{mmol} \mathrm{L}^{-1}$, respectively.

3.5.3. Accuracy and Precision. Accuracy and precision results are summarized in Table 2. For intraday assay, the accuracy 

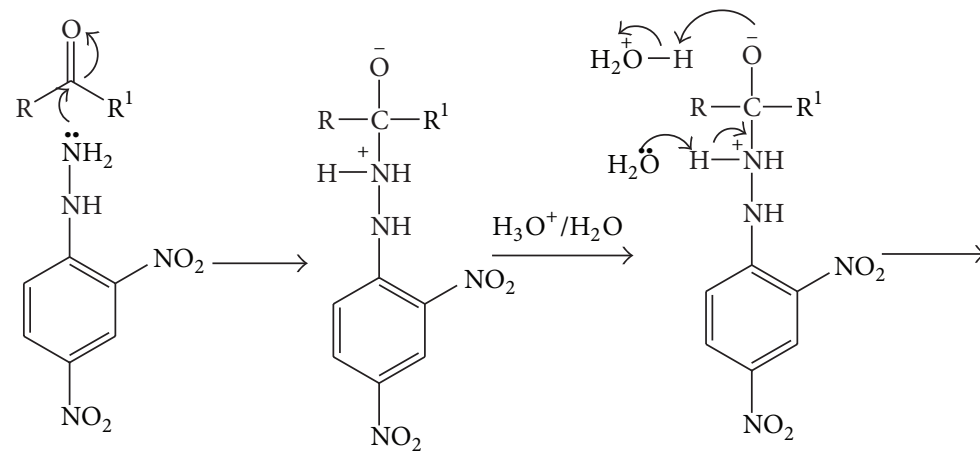<smiles>[R]C([R])(O)NNc1ccc([N+](=O)[O-])cc1[N+](=O)[O-]</smiles>

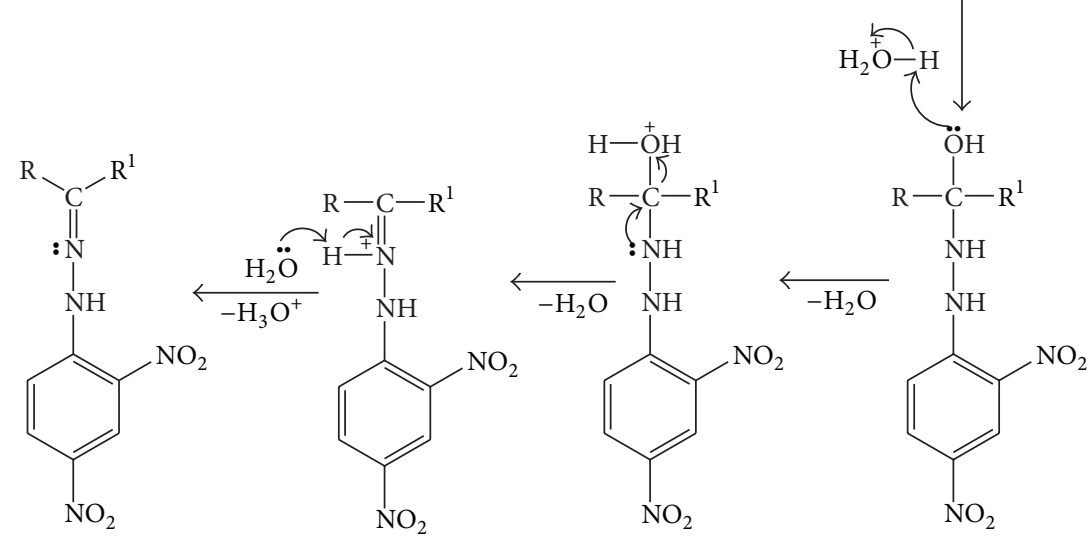

SCHEME 1: Mechanism of 2,4-dinitrophenylhydrazine to 2,4-dinitrophenylhydrazone.

for acetone in human plasma samples expressed as recovery was found as $98 \%$. For interday assay, the accuracy for acetone in human plasma samples expressed as recovery was found as $96 \%$.

\subsection{Mechanism of 2,4-DNPH to 2,4-Dinitrophenylhydrazone}

Brady's Test. 2,4-DNPH can be used to qualitatively detect the carbonyl functionality of a ketone such as acetone or aldehyde functional group. A positive test is signaled by a yellow, orange, or red precipitate known as a dinitrophenylhydrazone. If the carbonyl compound is aromatic, then the precipitate will be red; if aliphatic, then the precipitate will have a more yellow color [36]. The reaction between 2,4$\mathrm{DNPH}$ and a ketone such as acetone is shown below:

$$
\begin{aligned}
\mathrm{RR}^{\prime} \mathrm{C} & =\mathrm{O}+\mathrm{C}_{6} \mathrm{H}_{3}\left(\mathrm{NO}_{2}\right)_{2} \mathrm{NHNH}_{2} \\
& \longrightarrow \mathrm{C}_{6} \mathrm{H}_{3}\left(\mathrm{NO}_{2}\right)_{2} \mathrm{NHNCRR}^{\prime}+\mathrm{H}_{2} \mathrm{O}
\end{aligned}
$$

This reaction can be described as a condensation reaction, with two molecules joining together with loss of water. It is also considered an addition-elimination reaction: nucleophilic addition of the $-\mathrm{NH}_{2}$ group to the $\mathrm{C}=\mathrm{O}$ carbonyl group, followed by the removal of an $\mathrm{H}_{2} \mathrm{O}$ molecule. The mechanism of 2,4-DNPH to 2,4-dinitrophenylhydrazone is given in Scheme 1 [37].

2,4-DNPH does not react with other carbonyl-containing functional groups such as carboxylic acids, amides, and esters. For carboxylic acids, amides, and esters, there is resonance associated stability as a lone pair of electrons interacts with the p-orbital of the carbonyl carbon resulting in increased delocalization in the molecule. This stability would be lost by addition of a reagent to the carbonyl group. Hence, these compounds are more resistant to addition reactions. Also with carboxylic acids there is the effect of the compound acting as a base, leaving the resulting carboxylate negatively charged and hence unable to be attacked by this nucleophile $[36,37]$.

\section{Conclusions}

In this study, an analytical method was applied for the quantitative determination of acetone in human blood. The determination was carried out using a UV-Vis DAD detector with HPLC. In most of our patients' blood samples, high level of acetone has been determined. Higher levels of acetone have been measured in the patients who have high level of blood glucose and positive urine ketone (Group 1). The HPLC method based on the labeling of acetone with 2,4-DNPH seems to offer a rapid, low cost, sensitive, selective, and reproducible methodology for quantification of the acetone level in clinical samples such as human blood. The HPLC method described here overcomes many of the problems in the determination of acetone in biological fluids and the preanalytical errors. The volatile ketone is promptly stabilized by conversion into its DNPH derivative and rapidly determined without recourse to a solvent extraction step. The method uses very inexpensive reagents. As can be stated by Brega et al., the proposed HPLC method can therefore be used to great advantage over current gas chromatographic 
methods; it can be used in experiments requiring multiple samples and specific activity determination for the routine measurement of acetone in diabetic patients and in biological monitoring of exposed workers. The use of very small sample amounts makes this a favourable method in pediatrics [2].

We also presented acetone as a useful tool for the HPLC-based metabolomics investigation of endogenous metabolism and quantitative clinical diagnostic analysis. In the medical and medicolegal practice, the level of acetone could not be characteristic for a specific disease. However, the detection and early identification of acetone could be used as an initial indicator of detection of all these physiopathological conditions [7] and the biological monitoring test [2] and to determine further diagnostic management and timely treatment. Determination of acetone levels in blood may be a valid clinical approach in the symptomatic or/and nonsymptomatic cases in the literature for determining treatment strategy and controlling glycemic levels of patients. Consequently, the advanced studies which evaluate blood and urine ketone bodies level together should be performed in different physiopathological conditions including clinical and forensic toxicological studies.

\section{Competing Interests}

The authors declare no conflict of financial, academic, commercial, political, or personal interests.

\section{Acknowledgments}

This study was supported by Canakkale Onsekiz Mart University Scientific Research Projects Commission, Canakkale/ Turkey (Project no. TSA 2015-497), and was performed in Nanoscience and Technology Research and Application Center (NANORAC). The authors would like to thank all participants who kindly provided human blood and urine samples for the study and those who helped in the collection of samples at Canakkale Onsekiz Mart University Application and Research Hospital.

\section{References}

[1] D. J. Reisman, Acetone: First Draft, World Health Organization, Geneva, Switzerland, 1998.

[2] A. Brega, P. Villa, G. Quadrini, A. Quadri, and C. Lucarelli, "High-performance liquid chromatographic determination of acetone in blood and urine in the clinical diagnostic laboratory," Journal of Chromatography A, vol. 553, pp. 249-254, 1991.

[3] D. R. Cardoso, S. M. Bettin, R. V. Reche, B. S. Lima-Neto, and D. W. Franco, "HPLC-DAD analysis of ketones as their 2, 4-dinitrophenylhydrazones in Brazilian sugar-cane spirits and rum," Journal of Food Composition and Analysis, vol. 16, no. 5, pp. 563-573, 2003.

[4] F. Ullmann, W. Gerhartz, Y. S. Yamamoto, F. T. Campbell, R. Pfefferkorn, and J. F. Rounsaville, Ullmann's Encyclopedia of Industrial Chemistry, Federal Republic of Germany/DeerfieldBeach, Weinheim, Germany, 6th edition, 1985.

[5] P. M. Jenner, E. C. Hagan, J. M. Taylor, E. L. Cook, and O. G. Fitzhugh, "Food flavourings and compounds of related structure I. Acute oral toxicity," Food and Cosmetics Toxicology, vol. 2, pp. 327-343, 1964.

[6] M. P. Kalapos, "On the mammalian acetone metabolism: from chemistry to clinical implications," Biochimica et Biophysica Acta (BBA)_General Subjects, vol. 1621, no. 2, pp. 122-139, 2003.

[7] G. Teresiński, G. Buszewicz, and R. Madro, "Acetonaemia as an initial criterion of evaluation of a probable cause of sudden death," Legal Medicine, vol. 11, no. 1, pp. 18-24, 2009.

[8] M. M. Cartwright, W. Hajja, S. Al-Khatib et al., "Toxigenic and metabolic causes of ketosis and ketoacidotic syndromes," Critical Care Clinics, vol. 28, no. 4, pp. 601-631, 2012.

[9] L. Laffel, "Ketone bodies: a review of physiology, pathophysiology and application of monitoring to diabetes," Diabetes/Metabolism Research and Reviews, vol. 15, no. 6, pp. 412426, 1999.

[10] A. W. Jones, A. Sagarduy, E. Ericsson, and H. J. Arnqvist, "Concentrations of acetone in venous blood samples from drunk drivers, type-I diabetic outpatients, and healthy blood donors," Journal of Analytical Toxicology, vol. 17, no. 3, pp. 182185, 1993.

[11] J. A. Behre, "A modified salicylaldehyde method for determination of acetone bodies in blood and urine," The Journal of Biological Chemistry, vol. 136, no. 1, pp. 25-34, 1940.

[12] C. Thin and A. Robertson, "The estimation of acetone bodies," The Biochemical Journal, vol. 51, no. 2, pp. 218-223, 1952.

[13] R. H. Barnes and D. R. Drury, "Utilization of ketone bodies by the tissues in ketosis," Experimental Biology and Medicine, vol. 36, no. 3, pp. 350-352, 1937.

[14] G. Rooth and S. Ostenson, "Acetone in alveolar air, and the control of diabetes," The Lancet, vol. 2, no. 7473, pp. 1102-1105, 1966.

[15] J. Peinado, F. J. López-Soriano, and J. M. Argilés, "Gas chromatographic method for the estimation of acetone and its metabolites in biological samples," Journal of Chromatography B: Biomedical Sciences and Applications, vol. 415, no. 2, pp. 372376, 1987.

[16] F. J. López-Soriano and J. M. Argilés, "Simultaneous determination of ketone bodies in biological samples by gas chromatographic headspace analysis," Journal of Chromatographic Science, vol. 23, no. 3, pp. 120-123, 1985.

[17] T. Mitsui, N. Yuza, N. Kato, and T. Kondo, "Is acetone a normal breath constituent in Japanese?" Clinica Chimica Acta, vol. 280, no. 1-2, pp. 205-208, 1999.

[18] F. Y. Bondoc, Z. Bao, W.-Y. Hu et al., "Acetone catabolism by cytochrome P450 2E1: studies with CYP2E1-null mice," Biochemical Pharmacology, vol. 58, no. 3, pp. 461-463, 1999.

[19] M. K. Campbell and S. O. Farrell, Biochemistry, Cengage Learning, Boston, Mass, USA, 5th edition, 2006.

[20] American Diabetes Association, Ketoacidosis, http://www .diabetes.org/living-with-diabetes/complications/ketoacidosisdka.html.

[21] B. T. Garibaldi, A. O. Diallo, S. P. Bell, D. C. Files, and P. J. Troy, Patient Encounters: The Internal Medicine Work-Up, Lippincott Williams \& Wilkins, Philadelphia, Pa, USA, 2010.

[22] J. Schlatter, F. Chiadmi, V. Gandon, and P. Chariot, "Simultaneous determination of methanol, acetaldehyde, acetone, and ethanol in human blood by gas chromatography with flame ionization detection," Human and Experimental Toxicology, vol. 33, no. 1, pp. 74-80, 2014.

[23] S. Fujii, T. Maeda, I. Noge et al., "Determination of acetone in saliva by reversed-phase liquid chromatography with fluorescence detection and the monitoring of diabetes mellitus patients 
with ketoacidosis," Clinica Chimica Acta, vol. 430, pp. 140-144, 2014.

[24] R. F. Nascimento, J. C. Marques, B. S. Lima Neto, D. De Keukeleire, and D. W. Franco, "Qualitative and quantitative high-performance liquid chromatographic analysis of aldehydes in Brazilian sugar cane spirits and other distilled alcoholic beverages," Journal of Chromatography A, vol. 782, no. 1, pp. 1323, 1997.

[25] L. J. Papa and L. P. Turner, "Chromatographic determination of carbonyl compounds as their 2,4-dinitrophenylhydrazones II. High pressure liquid chromatography," Journal of Chromatographic Science, vol. 10, no. 12, pp. 747-750, 1972.

[26] M. X. Coutrim, L. A. Nakamura, and C. H. Collins, "Quantification of 2,4-dinitrophenyl-hydrazones of low molecular mass aldehydes and ketones using HPLC," Chromatographia, vol. 37, no. 3-4, pp. 185-190, 1993.

[27] K. Fung and D. Grosjean, "Determination of nanogram amounts of carbonyls as 2,4-dinitrophenylhydrazones by highperformance liquid chromatography," Analytical Chemistry, vol. 53, no. 2, pp. 168-171, 1981.

[28] ICH, "Validation of analytical procedures and methodology," in Proceedings of the International Conference on Harmonization (ICH '05), Geneva, Switzerland, 2005.

[29] NMKL, Validation of Chemical Analytical Methods, NMKL Procedure No 4, 3rd Version, 2009.

[30] G. E. P. Box, "Non-normality and tests on variances," Biometrika, vol. 40, no. 3-4, pp. 318-335, 1953.

[31] C. A. Markowski and E. P. Markowski, "Conditions for the effectiveness of a preliminary test of variance," The American Statistician, vol. 44, no. 4, pp. 322-326, 1990.

[32] S. Yilmaz, Electroanalytical Chemistry with Applied Examples, Gazi Kitabevi, Ankara, Turkey, 2016 (Turkish).

[33] D. A. Skoog, D. M. West, and F. J. Holler, Fundamentals of Analytical Chemistry, Sanders Colege, New York, NY, USA, 6th edition, 1992.

[34] O. Croitoru, A. Spiridon, I. Belu, A. Turcu-Ştiolică, and J. Neamţu, "Development and validation of an HPLC method for simultaneous quantification of clopidogrel bisulfate, its carboxylic acid metabolite, and atorvastatin in human plasma: application to a pharmacokinetic study," Journal of Analytical Methods in Chemistry, vol. 2015, Article ID 892470, 12 pages, 2015.

[35] S. Can, S. Yilmaz, G. Saglikoglu, M. Sadikoglu, and N. Menek, "Electrocatalytic oxidation of acyclovir on poly(paminobenzene sulfonic acid) film modified glassy carbon electrode," Electroanalysis, vol. 27, no. 10, pp. 2431-2438, 2015.

[36] G. Hill and J. Holman, Chemistry in Context, 5th edition, 2000.

[37] O. L. Brady and G. V. Elsmie, "The use of 2:4-dinitrophenylhydrazine as a reagent for aldehydes and ketones," The Analyst, vol. 51, no. 599, pp. 77-78, 1926. 

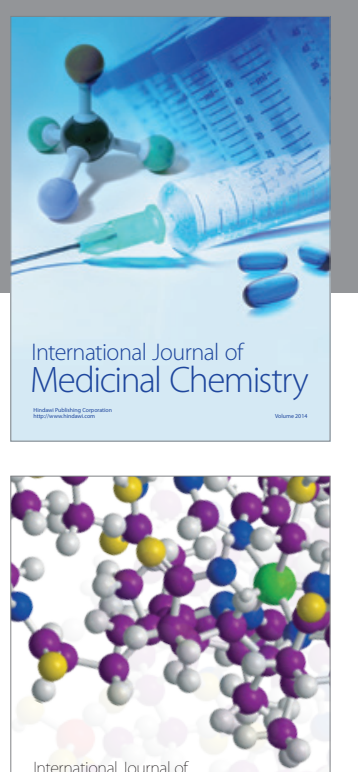

Carbohydrate Chemistry

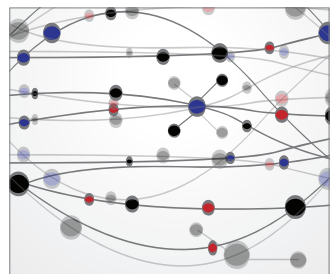

The Scientific World Journal
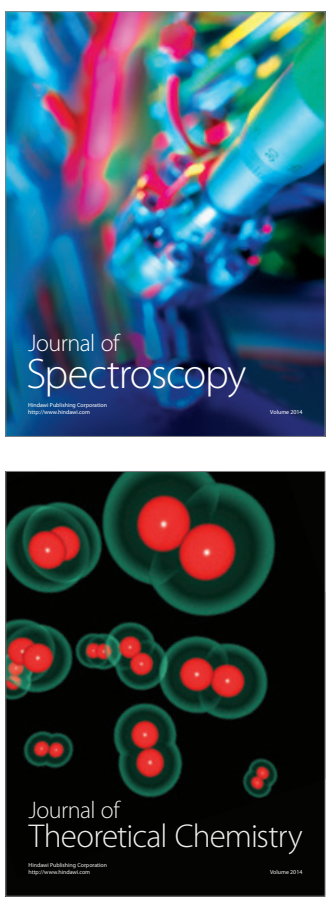
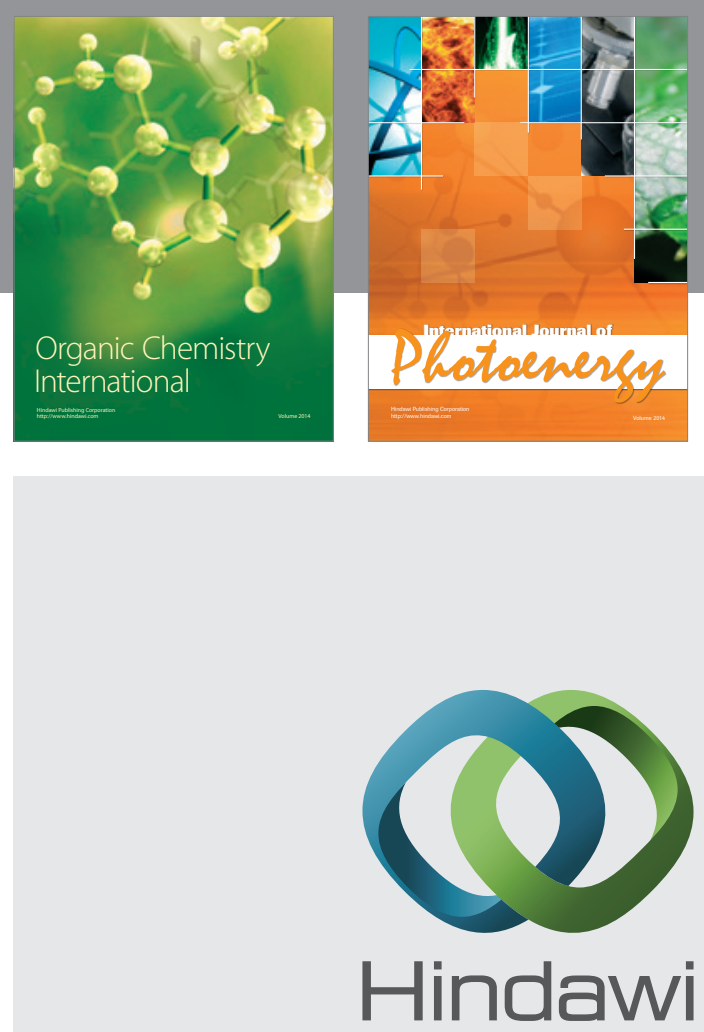

Submit your manuscripts at

http://www.hindawi.com

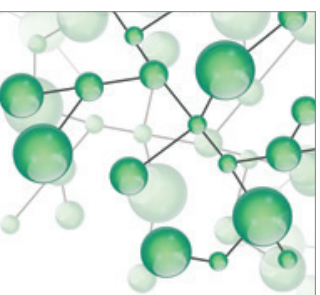

International Journal of

Inorganic Chemistry

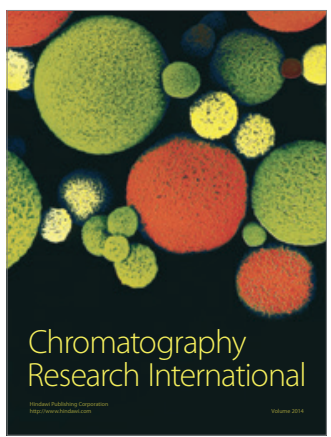

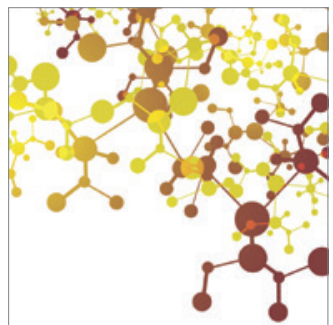

Applied Chemistry
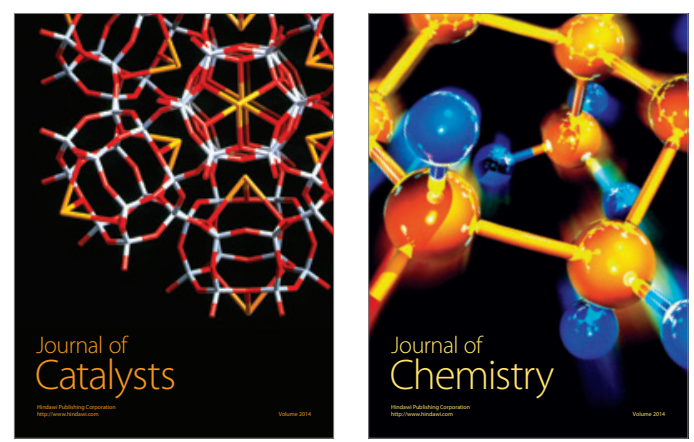
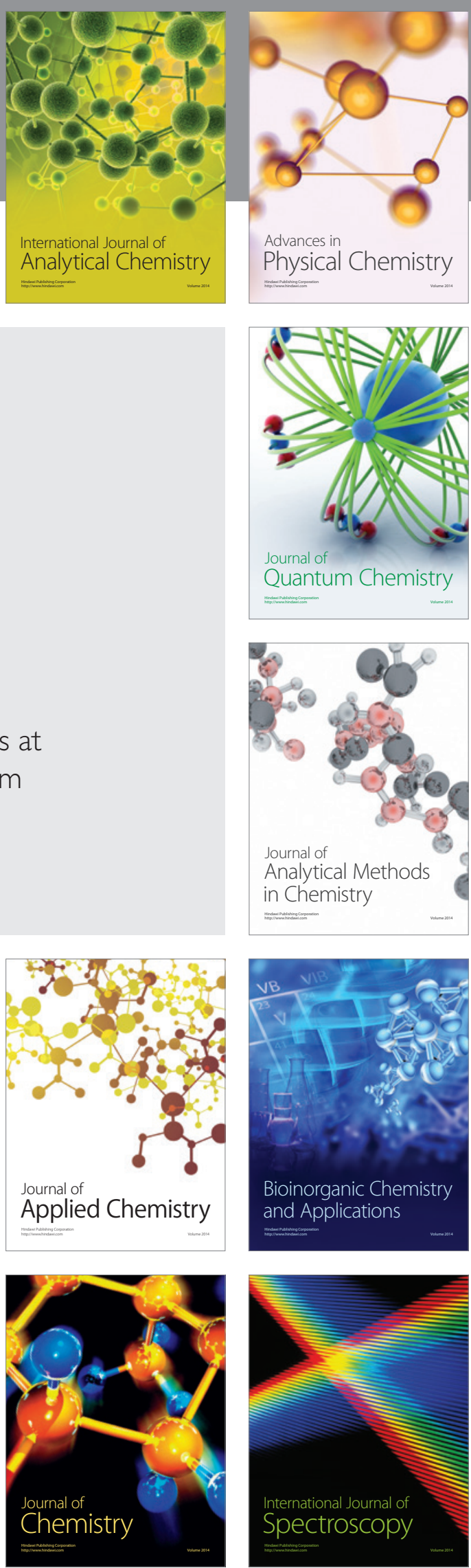